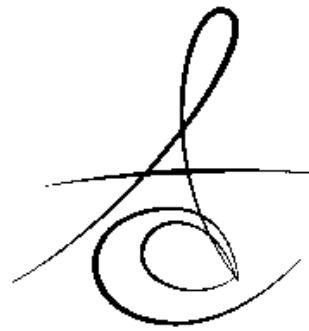

\title{
BAŞLANGIÇ LEZYONLARININ TEDAVISINDE REZIN INFILTRASYON TEKNIĞININ ETKINLIĞININ DEĞERLENDIRILMESI
}

\section{EVALUATION OF RESIN INFILTRATION TECHNIQUE AS A TREATMENT OPTION OF INITIAL CARIES LESIONS}

Dt. Esin EKİ*

Doç. Dr. Mesut Enes ODABAŞ *

Makale Kodu/Article code: 1904

Makale Gönderilme tarihi: 20.10.2014

Kabul Tarihi: 02.02.2015

\section{ÖZET}

Diş çürüğü ağız boşluğunu etkileyen en önemli hastalıklardan birisidir. Modern toplumlarda estetik ve kozmetik beklentilerin artması hastaları anestezi veya aşındırma gerektirmeyen daha ucuz tedavilere yönlendirmiştir. Doğal diş dokularının girişimsel olmayan yaklaşımlarla muhafaza edilmesi, en az müdahale diş hekimliğinin (Minimum intervention dentistry-MID) temel konseptini oluşturmaktadır. Aktif başlangıç mine çürük lezyonları olan beyaz nokta lezyonları, lezyon yüzeyi göreceli bütünlüğünü korumaya devam ederken, mine gövdesinde mineral kaybı ile karakterizedirler. Oluşumlarının temel nedenleri arasında uygun olmayan ev ağız bakım alışkanlıkları, yüksek şeker içerikli veya asidik gıdaların sık tüketilmesi ve ortodontik braket uygulamaları yer almaktadır. Beyaz nokta lezyonlarının tedavi seçenekleri; mikroabrazyon, fluorid ve kazein fosfopeptid-amorföz kalsiyum fosfat uygulamaları ve restoratif tedaviler olarak bilinmektedir. Beyaz nokta lezyonları kavitasyona öncülük edebilmektedirler. Ancak erken dönemde teşhis edilebildiklerinde remineralizasyon döngüsünün sonucu olarak gerileyebildikleri belirtilmekte bu nedenle restore edilmemeleri tavsiye edilmektedir. Bu derlemenin amacı başlangıç çürük lezyonlarının gelişimini, tedavi seçeneklerini açıklamak ve bu lezyonları durdurmak adına yeni geliştirilmiş minimal girişimsel bir konsept olan rezin infiltrasyon tekniğini tanıtmaktır.

Anahtar kelimeler: Başlangıç çürük lezyonları; Beyaz lezyonlar; İnfiltratif; Rezin infiltrasyon

\section{ABSTRACT}

Tooth decay is one of the major diseases affecting the oral cavity. In modern communities by rising expectance of cosmetic and esthetic, the patients prefer cheaper treatment options without any anesthetics or drilling. The preservation of natural tooth issues through non-invasive approaches drives the mainstream concepts in minimum intervention dentistry (MID). The white spot lesions are the active incipient enamel carious lesion and characterized by mineral loss in the bulk of the enamel, whilst the surface of the lesion remains relatively intact. The main reasons for their occurrence are unsuitable oral care routines at home, high sugar concentrated or acidic foods and orthodontic braces appliance. The treatment options of white spot lesions are known as microabrasion, fluorid and casein phosphopeptideamorpheus calcium phosphate applications and restorative treatments. White spot lesions could lead to cavitation but in case of early diagnosis, these lesions may regress as a result of the remineralization so that they are not suggested to be restorated. The aim of this review was to explain how initial caries lesions occur, treatment options and introducing a recently developed technique to arrest incipient caries lesions in a micro-invasive concept called resin infiltration.

Key words: Infiltrative; Initial caries lesions; resin infiltration; white spots

\section{GİRIŞ}

Kozmetik ve estetik gereksinimler tüm toplumlarda gittikçe değer kazanmakta ve hastalar tarafından diş tedavilerinde anestezi, frezle aşındırma gerek- tirmeyen ve daha uygun fiyatlı kozmetik uygulamaları tercih etmektedirler. ${ }^{1}$

Girişimsel olmayan yaklaşımlarla doğal diş dokularının korunması minimum müdahale diş hekimliğinin (minimum intervention dentistry-MID) ana konseptini oluşturmaktadır. ${ }^{2}$ Modern diş hekimliğinin

\footnotetext{
${ }^{*}$ İnönü Üniversitesi Diş Hekimliği Fakültesi Periodontoloji AD
} 
gelişmesi ile birlikte diş yapılarının korunması ve cerrahi tedavilerin önlenmesi popüler yöntemler arasında yerlerini almıştır. ${ }^{3}$

Diş çürüğü ağız boşluğunu etkileyen en önemli hastalıklardan birisidir. ${ }^{4}$ Çürük, diş plağındaki bakteriyel metabolizma sonucu üretilen asitlerin diş dokularında yaptıkları yıkım olarak tanımlanan ve etiyolojisi mikrobiyal faktörler, diyet, konak ve zaman arasındaki etkileşime dayanan multifaktöriyel bir hastalıktır. ${ }^{4,5}$

Çürük lezyonları, fluorid uygulamaları, uygun diyet yönlendirmeleri ve oral hijyen eğitimi gibi girişimsel olmayan yöntemlerle kontrol altında tutulabilir. Bu yöntemler uyumlu hastalarda kavitasyonun henüz oluşmadığı lezyonun ilerlemesini önleyebilmektetir. ${ }^{6}$ Diğer taraftan, girişimsel tedaviler, özellikle ara yüz lezyonlarında, çürük lezyonuna ulaşmak için belirgin miktarlarda sağlıklı diş dokusunun da kaldırımasını gerektirmekte ve restorasyon döngüsünü başlatmaktadır., ${ }^{6,7}$ En uygun tedavi protokolleri konusunda belirsizlikler mevcut olmakla birlikte radyografik olarak minenin iç tabakasına ya da dentinin dış $1 / 3$ tabakasına ulaşan lezyonlarda genellikle girişimsel tedavi tercih edilmektedir., ${ }^{7,8}$ Girişimsel işlemler şartlarda restorasyon döngüsünün başlamesı açısından mümkün olduğunca ertelenmelidir. ${ }^{8}$

\section{Başlangıç lezyonları}

Mine çürüklerinin klinik olarak ilk belirtisini beyaz lezyonlar oluşturmaktadır. ${ }^{\mathbf{5}}$ Çürük oluşumunun ilk basamakları süresince, yüzey tabakasından tükürük içerisine geçen çözünmüş mineral yarı dengeli bir durum oluşturmakta, mineraller yüzey tabakasında çökelmekte ve böylece minenin dış morfolojisinin korunmasını sağlamaktadır. Yüzey tabakası kısmi olarak pürüzlü hale geldiği için opağa dönüşmekte ve lezyon tebeşirimsi beyaz bir görüntü almaktadır. Her ne kadar translüsensi, minedeki demineralizasyonun erken işaretlerinden birisi olsa da tükürük tarafından maskelenebileceği için pek çok araştırmacı teşhis amaçlı hava ile kurutma işlemini tavsiye etmektedir. İlerleyen aşamalarda ise opaklık artmakta ve lezyon nemli koşullar altında bile görünebilmektedir. ${ }^{2}$

Birinci molar dişler, üst lateral kesiciler, alt kanin dişler beyaz lezyonlardan en çok etkilenen diş grubunu oluşturmaktadırlar. ${ }^{9}$ Bu lezyonların bukkal yüzeyde bulunması sıklıkla ortodontik braketler etrafındaki plak birikimine bağlı olarak gerçekleşmekte, çürüğe dönüşebilecekleri gibi dönüşmeden de kalabilmekte ve estetik problemlere neden olabilmekte- dirler. ${ }^{1,4,10,11}$ Her ne kadar, ortodontik sabit apareyler çıkarıldıktan sonra bu lezyonlar kısmi olarak remineralize olabilselerde tedaviden 5 yll sonra bile estetik problem oluşturabilmektedirler. ${ }^{11}$

Norveç'in kuzey kesiminde yapılan retrospektif bir çalışmanın sonucunda, ortodontik tedavi görmüş hastaların \%50'sinde tedavi süresince bir veya daha fazla sayıda beyaz lezyonun oluştuğu, ortodontik tedavi görmeyen hastalarda ise bu oranın labial yüzeylerde $\% 11$ olduğu belirlenmiştir. ${ }^{9}$

Beyaz lezyonların oluşumlarının diğer nedenleri uygun olmayan ev ağız bakım alışkanlıkları ve yüksek şeker ya da asit içerikli gıda tüketimidir. ${ }^{1}$ Bu lezyonların, erken dönemde belirlenmeleri durumunda remineralize olabilme intimalleri nedeniyle restore edilmemeleri tavsiye edilmektedir. 4, 5, 10

\section{Başlangıç lezyonlarında tedavi yaklaşımları}

Beyaz lezyonların tedavisinde 4 metot tavsiye edilmektedir. Bunlardan birincisi, pek çok çalışmada remineralizasyon yaparak beyaz noktaların gerilemesini sağladığı ifade edilen fluorid veya CPP-ACP uygulamalarıdır. ${ }^{1,10,11}$

Remineralizasyon kavitasyonun henüz oluşmadığı lezyonlarda, demineralizasyon sonrasında yüzey altı lezyonda kalan kristal artıkları üzerinde yeni bir yüzeyin oluşturulduğu, fluorid iyonları sayesinde asiste edilen, kalsiyum ve fosfat iyonları bağımlı bir doğal tamir döngüsüdür. ${ }^{5}$ Remineralizasyon teknikleri kısıtlı etkiye sahiptirler çünkü remineralizasyon sıklıkla lezyon yüzeyinde sınırıdır, uygulamaları zaman alıcıdır ve lezyon gelişiminin çok erken aşamalarında uygulanmaya başlanmaları gerekmektedir. ${ }^{11}$

Fluorid diş çürüklerinin kontrolünde ve önlenmesinde anahtar rolü oynamakla birlikte, uygulanmasının hasta uyumunun ileri derecede olmasını gerektirmesi, zararlı alışkanlıkların ortadan kaldırıması gerekliliği gibi nedenlerle her zaman başarılı olamamaktadır. ${ }^{5,10,11}$

İkinci metot, beyaz fluorozis lekelerini maskelemek için hidrojen peroksit ile beyazlatma tedavisidir ancak bu yöntemde estetik etki sınırlı olmakta, işlem sonrasında demineralize mine yüzeylerinde olduğu kadar sağlıklı mine yüzeylerinde de mikrosertlik azalabilmekte ve bu nedenle sıklıkla operasyon sonrası hassasiyet bildirilmektedir.

Üçüncü metot mikroabrazyondur. Bu teknik, mikroabrazyonun uygulanma sıklığına, süresine ve sayısına bağlı olarak agresif mine azalmasına neden

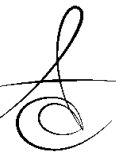


olabilmektedir. Ayrıca mikroabrazyon yalnızca sığ lezyonlarda bir tedavi seçeneği olarak ifade edilmektedir.

Dördüncü metot restoratif tedavidir. Girişimsel bir tedavi biçimi olan restoratif tedavi ile ilgili problem, beyaz lezyonlar için tedavi talep eden hastaların çoğunun çocuklar, adolesanlar veya genç erişkinler olmasıdır. Girişimsel prosedürler sıklıkla diş materyalinin gerektiğinden fazla uzaklaştııımasına dolayısıyla erken yaşta diş yıkımının hızlandırımasına neden olmaktadır. ${ }^{11}$

\section{Başlangıç Lezyonlarının Tedavisinde Yeni Bir Yaklaşım- Rezin İnfiltrasyon Yöntemi}

Beyaz lezyonları tedavi etmenin yeni bir minimal girişimsel yolu ise rezin infiltrasyon yöntemidir. Yöntem, ışıkla polimerize olan düşük yoğunluktaki rezinin hızlı bir şekilde pürüzlü yapıdaki mineye penetre olmasına dayanmaktadır. Rezin diş içerisindeki porları tamamen doldurmakta, kaybolan diş yapısının yerine geçmekte ve çürük ilerlemesini durdurmaktadır. ${ }^{1,10}$

Rezin infiltrantın sahip olması gereken özellikler: Hidrofilik ve bakteriostatik yapı, yüksek yüzey aktivitesi ile birlikte düşük viskozite, ağız dokularına karşı toksik etkinin olmaması, katı hale polimerize olabilme, ağız boşluğundaki mekanik ve kimyasal irritanlara karşı direnç, estetik açıdan kabul edilebilirlik ve yüksek penetrasyon kapasitesi şeklinde ifade edilmektedir. ${ }^{12}$ Rezin infiltrantın sahip olduğu çok düşük viskozite, yüksek yüzey gerilimi ve mine ile düşük bağlan$\mathrm{t}$ I açısı, asitle pürüzlendirilmiş mineye ve mine çürük lezyonu gövdesine penetrasyonlarını etkilemektedir. ${ }^{11}$ Rezin lezyon içerisine kılcal kuvvetler sayesinde penetre olmakta ve lezyon yüzeyinde değil içerisinde bir bariyer oluşturmaktadır. 1, 5,7

Rezin infiltrantın içeriği; Etch: Hidroklorik asit, pirojenik silisik asit, yüzey aktif maddeler, dry: $\% 99$ ethanol, infiltrant: metakrilat bazlı rezin matriks, inisiyatörler, ek maddeler şeklindedir. ${ }^{1}$ Tri-etilen glikol di-metakrilat (TEGDMA) içerikli rezin materyaller bisfenol glisidil metakrilat (BisGMA) içerikli olanlar ile karşılaştıııldıklarında, lezyonların ilerlemesini durdurmakta daha başarıı olarak bulunmuşlardır. Bu durum TEGDMA içerikli rezinlerin daha yüksek penetrasyon kapasitesine sahip olmalarıla bağlantılandırılmaktadır. ${ }^{6}$ Ancak TEGDMA bazı bir infiltrant içerisine etanol eklenmesi saf rezin ile karşışşııııldığında penetrasyon derinliğinde bir miktar azalmaya neden olmaktadır. ${ }^{14}$
Üretici firmanın önerileri çerçevesinde ICON (ICON®, DMG, Hamburg, Germany) rezin infiltrant uygulaması şu şekildedir; Icon-Etch $®$ 'in ilgili yüzeye 2 dakika uygulanması, uygulanan dişin yıkanması ve hava spreyi ile 30 saniye kurutulması, Icon-Dry ${ }^{\prime}$ 'n 30 saniye uygulanması ve hava spreyi ile kurutulması, Icon-Infiltrant $\AA^{\prime}$ 'n ilki 3 dakika uygulama ve 40 saniye Işınlama, ikincisi 1 dakika uygulama ve 40 saniye ışınlama şeklinde iki defa uygulanması, yüzeye politür işlemlerinin yapılması. ${ }^{13}$

Rezin infiltrasyonda kullanılan materyal tükürük varlığı gibi durumlarda hassastır bu nedenle modern klinik ekipmanların ve bir asistanın yardımının bulunması şarttır. ${ }^{15}$ Lezyonların yüzey düzenlemesi (conditioning) \%15'lik hidroklorik asit jel kullanılarak yapılmaktadır. ${ }^{1}$ Yapılan asitlemenin amacı rezin penetrasyonunu engelleme intimali bulunan daha yüksek oranda mineralize yüzey tabakasını ve yüzeysel renklenmeleri ortadan kaldırmaktır. ${ }^{1,2}$ Asitleme sonrasında etanol kullanılarak lezyonun kurutulması sağlanmakta, böylece rezin pürüzlü diş yapısına daha kolay penetre olmaktadır. ${ }^{1}$ Yapılan çalışmalar sonucunda $\% 15^{\prime}$ lik hidroklorik asit jelin \%37'lik fosforik asit jel ile karşılaştırıldığında daha etkin yüzey erozyonu sağladığı ifade edilmektedir. ${ }^{1,3,14}$

Rezin infiltrasyon yönteminin bir avantajı da mikroporözitelerin doldurulması sonucunda minedeki lezyonların beyaz görüntülerini kaybetmeleri ve sağılıkı mineye benzer görünüme bürünmeleridir. ${ }^{1}$ Bu mekanizma lezyon içerisindeki ışık dağıımına dayanmaktadır. Yapılan çalışmalar sonucunda minenin refraktif indeksi (R.I) 1.62 olarak bulunmuştur. Yüzey altı lezyonlarında ise porlar R.I. 1.33 olan su veya R.I. 1.0 olan hava ile doludur. Mine ve su/hava ortamının R.I. farklııkları ışık dağııımına etki etmekte ve lezyonun daha opak görünmesine neden olmaktadır. İnfiltrasyon uygulanmış lezyonların mikroporöziteleri ise R.I. 1.46 olan rezin ile doludur ve bu rezin suyun tersine buharlaşmamaktadır. Rezin infiltrant ve mine arasındaki bu R.I. farkı göz ardı edilebilir derecededir ve lezyonun, etrafındaki sağlıklı mine yapısına benzer görünmesini sağlar. ${ }^{1,11}$

Ara yüzey lezyonlarında sealing ve infiltrasyon uygulamalarına alternatif olarak sınıf 2 kavite restorasyon uygulamaları düşünülebilmekte, ancak bu uygulamalar çoğunlukla diş yapılarını gerektiğinden fazla uzaklaştırmakta ve $\% 100$ başarıyı garanti etmemektedir. ${ }^{3}$ Beyaz lezyonlarda olduğu gibi erken ara 
yüzey lezyonların tedavisinde de sealing ve infiltrasyon uygulamaları gibi girişimsel olmayan başarılı tedavi seçenekleriyle genç erişkinlerde ve çocuklarda diş yapılarının olabildiğince korunarak restorasyona gerek duyulmadan tedavi edilmesi önem kazanmaktadır. 3,5 Oklüzal yüzeydeki başlangıç lezyonlarında, biyofilm tabakasının besin desteğini yapan ağız ortamından izole edilebilmesi için yapılan pit ve fissür örtücü uygulaması çürük lezyonlarının ilerlemesini durdurmakta etkili bir yöntem olarak değerlendirilmekte ve girişimsel olmayan ve minimal girişimsel tedaviler arasında bir terapötik geçiş basamağı oluşturmaktadırlar. 2,6 Adeziv materyaller ile pit ve fissür örtücüler en azından kısmi olarak yapay lezyonlar içerisine penetre olabilmektedirler. ${ }^{6}$ Oklüzal çürüklerin ilerlemesini durdurmakta kullanılan etkinliği onaylanmış bu yöntemlerin aksine, ara yüzey ve serbest yüzey çürüklerinde bu yaklaşımların eksiklikleri bulunmaktadır. ${ }^{2}$ Ara yüzey sealing uygulamalarında seçilmiş tüm yüzeyler, teşhise ve lezyon yüzeyine dental materyalin uygulanmasına izin verebilecek şekilde çalışma alanının oluşturulması amacıyla separe edilmeye intiyaç duymaktadırlar., 5,15

İnfiltrasyon tekniği yeni bir teknik olmasa da ara yüzey lezyonları için uygulanması çok düşük yoğunluktaki rezin infiltrantların geliştirilmesi, daha etkin infiltrasyon protokolleri ve tek uygulamada yapılabilmelerini sağlayan özel uygulayıcı araçların kullanıma sunulmasıyla artmıştır. ${ }^{2}$ İnfiltrantın mevcut izolasyon sağlayıcı aracı ve difüzyon bariyerinin lezyonun dış yüzeyinde değil iç kısmında oluşturulması sayesinde separasyona gerek kalmamaktadır. 2, 3, 7, 8 Bir çok araştırmacı yüzeyel ara yüzey lezyonlarının tedavisinde rezin infiltrasyon uygulamasını önermektedir. ${ }^{16-21}$ Martignon ve arkadaşları ${ }^{3}$ tarafından yapılan randomize klinik çalışmada, infiltrasyon/sealing uygulamaları ara yüzey lezyonlarının ilerlemesinin kontrolünde plasebo grubu (30 saniye sadece firçanın diş yüzeyinde gezdirilmesi ve 2 dakika sonra uygulamanın tekrarlanması) ile karşılaştırılmış, 3 yılık takip sonucunda rezin infiltrantlarda başarı oranı \%68, sealing uygulamasında $\% 60$ ve plasebo grubunda $\% 30$ olarak bulunmuş, bu durum uygulamaların, mine dentin sınırındaki veya dentinin $1 / 3$ dış tabakasındaki aktif çürük lezyonlarında modern girişimsel olmayan yöntemler arasında yerini almasını sağlamıştır.

Paris ve arkadaşları ${ }^{7}$ tarafından yapılan bir çaIışmada, rezin infiltrasyon yöntemi ile plasebo tedavinin ara yüzey lezyonları üzerindeki etkinliği değerlen- dirilmiş, sonuçta, ara yüzey lezyonlarının ilerlemesini durdurmakta infiltrasyon yöntemi belirgin derecede üstün bulunmuştur.

Meyer-Lueckel ve arkadaşları ${ }^{22}$ tarafından yapılan bir randomize kontrollü klinik çalışmada, Rezin infiltrant uygulamasının ara yüzey başlangıç lezyonlarının tedavisinde placebo tedaviye karşı etkinliği değerlendirilmiştir. Çalışmaya 22 erişkinde, radyografik derinlikleri minenin iç yarısına ya da dentinin $1 / 3$ dış tabakasına kadar uzanan 29 çift lezyon dahil edilmiştir. Çalışmanın sonucunda radyografik olarak test lezyonlarının \% 4'ünde, kontrol lezyonlarının \% 42'sinde ilerleme belirlenmiştir. 3 yıllık takip sonrasında, ara yüzey lezyonların infiltre edilmesinin lezyonun ilerleme riskini düşürmekte etkin olduğu ileri sürülmüştür.

Ekstrand ve arkadaşları ${ }^{15}$ tarafından yapılan bir çalışmada ise, süt molar dişlerin ara yüzey yüzeysel çürüklerinin tedavisinde fluorid cila/Rezin infiltrant birlikte kullanımının yalnızca fluorid cila kullanımına karşı etkinliği değerlendirilmiştir. Araştırmada kontrol grubu olarak \%2.26 fluorid cila, test grubu olarak Rezin infiltrant ve sonrasında \%2.26 fluorid cila kullanımı seçilmiştir. Fluorid cila hem test hem de kontrol gruplarına ilk tedaviden 6 ay ve 12 ay sonra tekrar uygulanmıştır. Birinci yılın sonunda klinik olarak test lezyonlarının \%31'inde ve kontrol lezyonlarının \%67'sinde lezyon derinliğinde artış gözlenmiştir. Radyografik olarak ise test lezyonlarının \%23'ünde, kontrol lezyonlarının \%62'sinde ilerleme belirlenmiştir. Bunun sonucunda, hem radyografik hem de klinik olarak Rezin infiltrant/fluorid cilanın beraber kullanımı yalnızca fluorid cila kullanımına karşı belirgin derecede etkin bulunmuş ve rezin infiltrasyon süt molar dişlerdeki ara yüzey lezyonların ilerlemesini durdurmada umut verici bir yöntem olarak düşünülmüştür. Bu çalışma materyalin klinik şartlar altında test edildiği ilk çalışmadır. Çalışmada önlem olarak bu tip lezyonların tedavisinde etkinliği onaylanmış fluorid uygulaması tüm lezyonlara yapılmıştır.

Doğal çürük lezyonlarında penetrasyon yapay olanlara oranla daha yavaş olmaktadır. Bu durumun hidroklorik asit ile asitleme sonrasında bile doğal lezyonların yüzey erozyonun yetersiz olması sonucunda olabileceği gibi, bu lezyonların protein ve karbonhidrat gibi daha çok organik materyale maruz kalması olabileceği ifade edilmiştir. ${ }^{14}$

Paris ve Meyer-Lueckel ${ }^{6}$ tarafından yapılan bir in-vitro çalışmada, infiltrantların, penetrasyon katsayısı 
(Penetration coefficient-PC) ve içeriklerine bağlı olarak, ara yüz doğal çürük lezyonlarının ilerlemesini durdurma özelliği değerlendirilmiştir. Kavitasyonun henüz oluşmadığı lezyonlar öncelikle \%15'lik hidroklorik asit ile pürüzlendirilmiş, daha sonra 5 dakika süreyle $P C$ değişiklik gösteren (PC63, PC185, PC204 ve PC391) deneysel rezinlerle infiltre edilmişlerdir. Pozitif kontrol grubu olarak akışkan kompozit rezinle kaplanmış lezyonlar, negatif kontrol grubu olarak herhangi bir işlem yapılmamış lezyonlar belirlenmiştir. Örnekler 400 gün süre ile $\mathrm{pH} 4.95$ olan demineralizasyon solüsyonunda bekletilmişlerdir. Bu solüsyon ile yapılan demineralizasyon işleminin 13 yıl süresince günde 2 saat boyunca demineralizasyon etkenlerine maruz kalmaya denk geldiği belirtilmektedir. Mineral kaybındaki ilerleme transvers- dalga boyu bağımsız mikroradyografi ile analiz edilmiştir. Çalışma sonucunda negatif kontrol grubunda, PC63 ve PC185 gruplarındaki mineral kaybı, pozitif kontrol grubu, PC204 ve PC391 gruplarına göre belirgin oranda daha yüksek bulunmuştur. Bu sonuçlara göre, PC>200 olan infiltrantların lezyonlardaki ilerlemeyi durdurma kapasitesine sahip olduğu düşünülmektedir.

Rezin infiltrasyonun kavitasyonun oluşmadığı ara yüzey lezyonlarında daha fazla demineralizasyonu önlediği belirtilmekle ancak, kavitasyonun oluştuğu lezyonlardaki etkinliği bilinmemektedir.

Paris ve arkadaşları 23 tarafından yapılan çalışmada, International Caries Detection Assessment System (ICDAS) kodları değişiklik gösteren (ICDAS kod 2-5) ara yüzey lezyonlarındaki infiltrasyon paternlerini değerlendirilmiştir. Çekilmiş insan molar ve premolar dişlerine rezin infiltrant uygulanmış, her bir lezyondan hazırlanan üçer kesit, dual-fluoresans boyama tekniği ve konfokal mikroskop kullanılarak analiz edilmiştir. Demineralize alanlar ortalama \%73'ten \%100'e varan oranlarda infiltre olabilirken, kaviteler yalnızca \%0-5 gibi önemsiz oranlarda doldurulabilmiştir. ICDAS kodu 5 olan kaviteler, ICDAS kodu 2 ve 3 olan kavitelerle karşılaştırıldıklarında belirgin olarak daha düşük yüzdelerde infiltrasyon/dolgu göstermişlerdir. Çalışmanın sonucunda, in-vitro şartlar altında, test edilen infiltrantın demineralize mine bölümlerinin çoğuna penetre olduğu belirlenmiştir. Demineralize pürüzlü yapdaki minenin herhangi ek bir işlem yapılmadan rezini yapısına alabilecek derecede yüksek kılcal kuvvetlere sahipken, kavitelerde kılcal kuvvetin dolgu yapabilmek için çok zayıf olduğu, bu nedenlerle daha büyük kavitasyonlarda infiltrant etkinliğinin zayıflaya- bileceği ifade edilmiştir.

Arnold ve Gaengler ${ }^{24}$ tarafından yapılan bir pilot çalışmada değişik tipte başlangıç yüzey altı çürük lezyonları minelerindeki pürüzlü yapı sodyum fluoresans dye ile doyurulduktan sonra infiltre edilmiştir. Lezyon boyunca alınan seri kesim örnekler polarize ışık mikroskobu, fluoresans mikroskobu ve simultane olarak her iki teknikle birden incelenmiştir. Aynı örnekler daha sonra tarama elektron mikroskobu ve EDXelement analizleri ile rezinin infiltrasyonunu onaylamak amacıyla değerlendirilmiştir. EDX kalsiyum ve fosfor sinyalleri lezyon yayılımı ile negatif bağlantı, karbon sinyalleri pozitif bağlantı sonucunda rezin infiltrasyonunun lezyondaki por hacmine bağımlı olduğunu göstermiştir. Veriler kombine tekniklerin rezinin sert dokulara infiltrasyonu hakkında daha fazla ve güvenilir bilgiler sağladığını ortaya koymuştur. İnfiltrasyonu değerlendirmekte rutin olarak kullanılan konfokal lazer mikroskobu ise lezyon morfolojisinin incelenmesine izin vermemesi açısından dezavantajlı bulunmuştur.

Yapılan çalışmalar değerlendirildiğinde rezin infiltrasyonun avantajları; demineralize mineye mekanik stabilizasyon sağlaması, hem uygulanan dişin hem de kontağı olan komşu dişin sağlam sert dokularını koruması, yüzeyel mikroorganizmalara ve kavitelere daimi tıkama sağlaması, porların ve derin demineralize alanların tıkanmasını sağlaması, lezyonun ilerlemesini durdurması, sekonder çürük riskini minimalize etmesi, uzun süreçlerde restoratif girişimleri geciktirmesi, operasyon sonrası hassasiyet ya da pulpal inflamasyon riski olmaması, gingivitis ya da periodontitis riskini azaltması, labial yüzeylerdeki demineralize alanları maskelemek için kullanıldığında estetik bozuklukları düzeltmesi ve yüksek hasta onayının söz konusu olması olarak ifade edilmektedir. ${ }^{12}$ Her ne kadar tüm bu girişimsel olmayan yöntemler minenin mikrosertliğini artırmakta pozitif etki yapıyor olsalar da, çürük lezyonlarının ilerlemesini durduran herhangi bir tekniğin, biyofilm bağımlı çürüklerin kontrolü mekanizmasını temel alarak değerlendirilmesi ve diyet kontrolü ile birlikte diş fırçalama alışkanlıkları ile desteklenmesi gerektiği belirtilmektedir. ${ }^{5}$

\section{KAYNAKLAR}

1. Shivanna V, Shikumar B. Novel treatment of white spot lesions: A report of two cases. J Conserv Dent 2011; 14: 423-6.

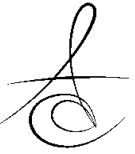


2. Belli R, Rahiotis C, Schubert EW, Baratieri LN, Petschelt A, Lohbauer U. Wear and morphology of infiltrated white spot lesions. J Dent 2011; 39: 376-85.

3. Martignon S, Ekstrand KR, Gomez J, Lara JS, Cortes A. Infiltrating/ Sealing proksimal caries lesions: A 3-year randomized clinical trial. J Dent Res 2012; 91: 288-92.

4. Torres CRG, Borges AB, Torres LMS, Gomes IS, de Oliveira RS. Effect of caries infiltration technique and fluorid therapy on the colour masking of white spot lesions. J Dent 2011; 39: 202-7.

5. Torres CRG, Rosa PCF, FerRezin infiltrantra NS, Borges $A B$. Effect of caries infiltration technique and fluorid therapy on microhardness of enamel carious lesions. Oper Dent 2012; 37: 363-9.

6. Paris $\mathrm{S}$, Meyer-Lueckel $\mathrm{H}$. Infiltrants inhibit progression of natural caries lesions in vitro. J Dent Res 2010; 89: 1276-80.

7. Paris S, Hopfenmuller W, Meyer-Lueckel H. Resin infiltration of caries lesions: an efficiacy randomized trial. J Dent Res 2010; 89: 823-6.

8. Paris $\mathrm{S}$, Meyer-Lueckel $\mathrm{H}$. Inhibition of caries progression by resin infiltration in situ. Caries Res 2010; 44: 47-54.

9. Oogard B. White spot lesions during orthodontic treatment: mechanisms and fluorid preventive aspects. Seminars in Orthod 2008; 14: 183-93.

10. Ekizer A, Zorba YO, Uysal T, Ayrikcil S. Effects of demineralization-inhibiton procedures on the bond strength of brakets bonded to demineralized enamel surface. Korean J Orthod 2012; 42: 17-22.

11. Kim S, Kim EY, Jeong TS, Kim JW. The evaluation of resin infiltration for masking labial enamel white spot lesions. Int J Paediatr Dent 2011; 21: 241-8.

12. Kielbasa AM, Müller J, Gernhardt CR. Closing the gap between oral hygiene and minimally invasive dentistry: a review on the resin infiltration technique of incipient (proximal) enamel lesions. Quintessence Int 2009; 40: 663-81.

13. http://www.dmg-dental.com/products/cariesinfiltration/icon/.

14. Meyer-Lueckel $H$, Paris $S$. Infiltration of natural caries lesions with experimental resins differing in penetration coefficents and ethanol addition. Caries Res 2010; 44: 408-14.

15. Ekstrand KR, Bakhshandeh A, Martignon S. Treatment of proximal superficial caries lesions on primary molar teeth with resin infiltration and fluorid varnish versus fluorid varnish only: efficiacy after 1 year. Caries Res 2010; 44: 41-6.

16. Mueller J, Meyer-Lueckel H, Paris S, Hopfenmuller W, Kielbassa AM. Inhibition of lesion progression by the penetration of resins in-vitro: influence of the application procedure. Oper Dent 2006; 31: 338-45.

17. Meyer-Lueckel H, Paris S, Kielbassa AM. Surface layer erosion of natural caries lesions with phosphoric and hydrochloric acid gels in preparation for resin infiltration. Caries Res 2007; 41: 223-30.

18. Meyer-Lueckel $H$, Paris S. Progression of artificial enamel caries lesions after infiltration with experimental light curing resins. Caries Res 2008; 42: $117-24$.

19. Meyer-Lueckel $\mathrm{H}$, Paris $\mathrm{S}$. Improved resin infiltration of natural caries lesions. J Dent Res 2008; 87: 1112-6.

20. Paris $S$, Meyer-Lueckel $H$, Cölfen $H$, Kielbassa AM. Resin infiltration of articial enamel caries lesions with experimental light curing resins. Dent Mater ] 2007; 23: 742-8.

21. Paris $S$, Meyer-Lueckel $H$, Cölfen $H$, Kielbassa AM. Penetration coefficients of commercially available and experimental composites intended to infiltrate enamel carious lesions. Dent Mater 2007; 23: 7428.

22. Meyer-Lueckel H, Bitter $\mathrm{K}$, Paris S. Randomized controlled clinical trial on proximal caries infiltration: three-year follow-up. Caries Res 2012; 46: 544-8.

23. Paris $S$, Bitter $K$, Naumann M, Dörfer CE, MeyerLueckel $H$. Resin infiltration of proximal caries lesions differing in ICDAS codes. Eur J Oral Sci 2011; 119: 182-6.

24. Arnold WH, Gaengler P. Light- and electronmicroscopic study of infiltration of resin into initial caries lesions-a new methodological approach. J Microsc 2012; 245: 26-33.

\section{Yazıșma Adresi}

Dt. Esin EKİZ

Gazi Üniversitesi Diş Hekimliği Fakültesi Pedodonti A.D.

8. Cd 82. Sk No: 406510

Emek, ANKARA, TÜRKİYE

Tel: +90 3122034089

e-posta: dt.esinekiz@gmail.com 